\title{
A MEDICALIZAÇÃO NA ESCOLA A PARTIR DA PERSPECTIVA DE PROFESSORES DE EDUCAÇÃO INFANTIL: UM ESTUDO NA REGIÃO DE SOROCABA-SP
}

\author{
Marcos Roberto Vieira GARCIA ${ }^{1}$ \\ Lenna Nascimento BORGES ${ }^{2}$ \\ Patrícia de Paulo ANTONELI ${ }^{3}$
}

RESUMO: O artigo parte de considerações teóricas sobre o processo de medicalização da vida, em sua interface com a instituição escola e apresenta pesquisa qualitativa feita na região de Sorocaba-SP. A pesquisa envolveu a análise de entrevistas semiestruturadas com seis professoras de Educação infantil, com o objetivo de investigar seus discursos acerca do processo de medicalização na escola. Os resultados mostraram a percepção por parte dessas professoras da intensificação desse processo nas escolas onde trabalham e ao mesmo tempo um predomínio de apoio explícito ou implícito a ele, sendo a medicalização vista predominantemente sob um viés positivado. Eventuais problemas, como o excesso de diagnósticos ou possíveis efeitos colaterais de medicações, são apontados como fruto de diagnósticos e prescrições errados, e não como consequência do processo de medicalização em si. As famílias que resistem ao processo foram apresentadas de forma negativada, como superprotetoras ou negligentes em relação ao cuidado adequado de seus filhos. Não apareceram críticas à possível incapacidade da escola em lidar com crianças que fogem ao modelo de aluno ideal, o que mostra o processo de medicalização atrelado a um processo de disciplinarização na escola, por meio da atribuição de anormalidade aos alunos dissidentes em relação ao que é esperado.

PALAVRAS-CHAVE: Medicalização. Disciplinarização. Normalidade. Educação infantil.

\section{Introdução}

A medicalização na escola tem sido objeto da atenção crescente por parte de pesquisadores que se voltam ao entendimento da relação entre saúde mental e escola, sendo entendida como algo que se relaciona a um fenômeno maior, que é a medicalização da vida. O presente artigo visa contribuir para ampliar a discussão sobre o tema, a partir da apresentação de uma pesquisa realizada com discursos de professores sobre o tema.

\footnotetext{
${ }^{1}$ Docente do PPG em Educação. UFSCar - Universidade Federal de São Carlos. Sorocaba - SP - Brasil. 18052-780 - marcosvieiragarcia@gmail.com.

${ }^{2}$ Docente do curso de Pedagogia. UFSCar - Universidade Federal de São Carlos. Sorocaba - SP - Brasil. 18052-780 - lenna.nasc@ gmail.com.

${ }^{3}$ Mestranda em Educação. UFSCar - Universidade Federal de São Carlos. Sorocaba - SP - Brasil. 18052-

780 - patriciaantoneli@gmail.com.
} 
A expressão "medicalização da vida" foi inicialmente utilizada por Illich (1975) para descrever a inserção crescente dos saberes médicos, e seu aparato denominado de "progresso científico" em campos da vida individual que passam a ser submetidos a explicações e intervenções médicas. Illich interpreta esses sintomas como males típicos de uma civilização superindustrializada e, ainda, afirma que essa ampla intervenção médica na vida cotidiana acaba por causar muitos prejuízos à sociedade, sendo um deles o que o autor chama de iatrogênese (iatros - médico; gênesis - origem). "Em sentido estrito, uma doença iatrogênica é a que não existiria se o tratamento aplicado não fosse o que as regras da profissão recomendam" (ILLICH, 1975, p.23). Amplia o uso do conceito medicalização, pois analisa a apropriação, pela sociedade, dos saberes médicos reconhecidos como discurso com efeitos de verdade nas mais diferentes esferas sociais, disciplinando e governando a vida de todos e de cada um.

Foucault (2011) faz referência ao processo de medicalização relacionando-o à constituição de uma sociedade na qual o indivíduo e a população são governados por saberes originados da medicina. Neste sentido, ele refere o desenvolvimento de um poder sobre a vida, a partir do qual os saberes médicos passam a permear todas as esferas sociais e, constituem-se como relações de poder. Estas práticas conduzem, movimentam, se espalham, funcionam como uma maquinaria social que não está situada em um lugar e se dissemina por toda a estrutura social. Também em uma perspectiva foucaultiana, Machado (1978) utiliza o termo "medicalização da sociedade" afirmando ser este processo intensificado na atualidade. Para este autor, a "medicalização da sociedade" é o processo pelo qual a medicina passa a intervir sistematicamente na sociedade a partir do século XIX, calcada na expansão de uma nova tecnologia de poder voltada a "controlar os indivíduos e as populações, tornandoos produtivos ao mesmo tempo que inofensivos" (MACHADO, 1978, p.156), utilizando-se do projeto de transformação do desviante em um ser normalizado.

A medicalização, portanto, refere-se à expansão do saber médico sobre aspectos da vida que antes não eram alvo desse saber, não eram teorizados pela medicina, não sofrendo, por isso, intervenções de natureza médica. Difere do que poderia ser denominado "medicamentação" - que se refere à intervenção medicamentosa, química, uma vez que a medicalização é um processo que pode ou não requerer intervenção química - pois, para além disso, refere-se ao fato de se transformar em patologia o que não é. Seguindo esta lógica, a medicalização é um processo de cunho moral que, por meio de um investimento contínuo no corpo, busca conduzir as condutas dos indivíduos 
para o interior do sistema de normas culturais estabelecidas. Collares e Moysés (1994) assim a conceituam:

O termo medicalização refere-se como o processo de transformar questões não-médicas, eminentemente de origem social e política, em questões médicas, isto é, tentar encontrar no campo médico as causas de soluções para problemas desta natureza. A medicalização ocorre segundo uma concepção de ciência médica que discute o processo saúde-doença centrado no indivíduo, privilegiando a abordagem biológica, organicista. Daí as questões médicas serem apresentadas como problemas individuais, perdendo sua determinação coletiva. Omite-se que o processo saúde-doença é determinado pela inserção social do indivíduo, sendo, ao mesmo tempo, a expressão do individual e do coletivo (COLLARES; MOYSÉS, 1994, p.25).

De forma crescente e intensa, medicamentos são utilizados para propósitos que extrapolam a função precípua para a qual, em tese, foram sendo descobertos e criados, isto é, aliviar sintomas e curar doenças. Interesses mercantis incentivam, fortemente, a crença na "pílula mágica", pretensa solução para tudo (BARROS, 2010, p.89). Nesse sentido, Moysés afirma: "Com o consentimento da sociedade, que delega à medicina a tarefa de normatizar, legislar e vigiar a vida, estão colocadas as condições históricas para medicalização da sociedade, aí incluídos comportamento e aprendizagem" (MOYSÉS; COLLARES, 2008, p.1).

Para entender a mudança que vem ocorrendo nos últimos anos na forma de redefinição dos sofrimentos humanos cotidianos, é fundamental colocar em jogo a intersecção das novas produções científicas com os novos procedimentos diagnósticos, o desenvolvimento e marketing da indústria farmacêutica e a difusão, no senso comum, dos fundamentos biológicos do que é próprio do humano. No entanto, não se trata de fazer frente a um desenvolvimento no campo científico que trouxe grandes contribuições para o tratamento dos sofrimentos psíquicos - nem tampouco advogar em favor do abandono das pesquisas biológicas - mas exercer com cuidado a crítica de seus efeitos, quando disseminados no espaço social como visão hegemônica acerca da subjetividade.

Caminhando ao lado da medicalização temos o aumento monumental do uso de medicamentos psicotrópicos. Roudinesco (2000); Birman (2001); Aguiar (2004), dentre outros, têm se debruçado sobre este fato, analisando-o do ponto de vista das modificações do sistema capitalista, dos efeitos do consumo na vida subjetiva, das recodificações das experiências humanas em termos biológicos. A socialização do DSM (Manual de Diagnóstico e Estatística das Perturbações Mentais, publicado pela 
Associação Americana de Psiquiatria) na formação médica geral e em outros campos revela a banalização do diagnóstico e o uso irrestrito de medicações como intervenção diante da vida (GUARIDO, 2007). Observa-se, segundo pesquisa da UM-INCB (2008), um fenômeno mundial da expansão de uso de psicotrópicos, reproduzido também em nosso pais. O crescimento da produção do metilfenidato (conhecido pelas marcas registradas Ritalina e Concerta e comumente prescrito para os quadros de TDAH e dislexia) exemplifica essa expansão, pelo curto espaço de tempo em que ocorreu e pela quantidade produzida, levando-nos a refletir sobre as causas deste crescimento notório. No período de 2003 a 2012, o consumo de metilfenidato aumentou 775\% no Brasil. Os números subiram de $94 \mathrm{~kg}$ consumidos no ano de 2003, para $875 \mathrm{~kg}$ no ano de 2012. Já a importação da substância cresceu 373\%, aumentando de $122 \mathrm{~kg}$ em 2003 para $578 \mathrm{~kg}$ em 2012, crescimento, portanto de $775 \%$. Dados ainda mais recentes obtidos pela Agência Nacional de Vigilância Sanitária (Anvisa) confirmam essa alta apontando que o número de caixas de metilfenidato vendidas no país passou de 2,1 milhões em 2010 para 2,6 milhões em 2013 (ORTEGA, 2010).

Falar sobre medicalização é discutir o modo como se tem construído, apoiandose em uma racionalidade médica, estratégias de gestão da vida em todas as suas instâncias. São muitas as formas de controlar, disciplinar e conduzir os modos de ser. Trata-se desde intervenções químicas no organismo até intervenções terapêuticas ou pedagógicas que visam à transformação do sujeito objetivando enquadrá-lo à norma construída em determinada época e local. No ambiente escolar a medicalização é um processo de produção discursiva que justifica as dificuldades de aprendizagem, os comportamentos, ou seja, questões atinentes às situações cotidianas vividas nesse contexto, como sintomas de patologias.

A medicalização na escola é um fenômeno tributário desse processo maior da medicalização da vida, mas que merece ser investigado em suas particularidades, uma vez que mostra a consolidação do discurso psiquiátrico como pano de fundo para a construção de um modelo de aluno. O discurso médico influencia a educação e a conduta dos educadores, que levam para a sala de aula uma concepção de criança e adolescente que deve atender a um modelo pré-determinado socialmente, o que acaba provocando equívocos sobre a dicotomia normal-patológico. E essa concepção não permite que ele veja a criança e o adolescente como um ser atravessado historicamente, o que pode transformar o seu discurso no discurso de um sujeito universal, obedecendo de forma padronizada às características biológicas próprias da idade à qual pertence. 
Essas peculiaridades resultam de uma uniformização, produzindo uma homogeneização da educação (LUENGO; CONSTANTINO, 2010).

Uma breve retrospectiva das ideias contidas nas explicações sobre o fracasso escolar indicam três concepções principais presentes em textos de autores que de alguma forma tratam do tema. No início do século XX, médicos, sobretudo psiquiatras, usam a palavra "anormal" para qualificar os indivíduos com problemas de aprendizagem, atribuindo-se as causas das dificuldades aos distúrbios orgânicos. Esse momento histórico coincide com o início da medicina experimental, sendo um dos expoentes Lombroso (1835-1909) que argumentava ser a criminalidade um fenômeno físico e hereditário, as explicações para o fracasso escolar seguem o mesmo modelo determinista. Os ideais eugênicos se disseminam pelo mundo, o que pode ser percebido pelos textos da época, em que higiene mental se confunde com eugenia (BASTOS, 1999). Patto (1990) afirma que no início do século XX a determinação dos "anormais" e sua segregação já era uma prática social de competência médica e evidencia que muitos médicos "tiveram uma participação decisiva na constituição teórica e instrumental da psicologia educacional, direcionando-a, para a aquisição de uma identidade baseada no modelo médico" (PATTO, 1990, p.63).

Já nos anos 1930 há uma mudança na percepção das causas do fracasso escolar: sai-se de um período de determinismo e se pensa em prevenção. Nesse período as crianças que apresentam problemas de ajustamento ou de aprendizagem escolar passam a serem denominadas "crianças problema", substituindo o termo anormal, agora focalizando a influência ambiental. Ideias preventivistas e de forte apelo moral encontram-se presentes nesse momento histórico, onde a proposta não é de exclusão das crianças e sim de sua adequação. Aqui aparece uma vertente psicologizante das dificuldades de aprendizagem escolar, onde se utiliza conceitos oriundos da psicanálise que são traduzidos do ponto de vista da moral. Acredita-se que as causas para os déficits de rendimento escolar são orgânicas e psicossociais, devendo haver um ajuste psicológico do aluno para que se consiga uma correção das suas "inferioridades corpóreas", em geral imputada à classe social menos favorecida. Para isso se considera importante a boa alimentação e os hábitos higiênicos (BASTOS, 1999).

Nos anos 1960 nos EUA e na década seguinte no Brasil, a explicação para o fracasso escolar é focalizada na "carência cultural", atribuindo-se o mau desempenho escolar de alunos pobres, negros e imigrantes à ausência de estímulos culturais. Naquele momento, a explicação dada para as diferenças passava pela cultura, acreditando-se 
existirem culturas adiantadas e culturas atrasadas, sendo as condições ambientais as geradoras de deficiência. Essa teoria foi assimilada por órgãos brasileiros de política educacional, gerando programas compensatórios implementados nas escolas (BASTOS, 1999; LINS, 2010). Neste mesmo caminho, os trabalhos de Maria Helena Souza Patto discutiram amplamente a produção do fracasso escolar, como fruto dos efeitos de discriminação das classes trabalhadoras, justificada pelo discurso científico psicologizante. Para Patto (2000), a desigualdade e a exclusão são justificadas cientificamente, através do discurso patologizante e com explicações que ignoram a sua dimensão política e se centram no plano das diferenças individuais de capacidade. Seja atribuindo a "causa" do fracasso escolar a características internas do individuo, seja à “ausência de estimulação" por parte do ambiente, a patologização dos indivíduos é parte de um processo de ocultação das desigualdades sociais e por isto, exige um trabalho crítico, capaz de realizar rupturas e desenvolver novos posicionamentos.

Com a expansão mundial dos diagnósticos psiquiátricos e das prescrições de psicotrópicos concomitante, a medicalização na educação passa cada vez mais a direcionar-se a todas as crianças, ultrapassando as barreiras de classe. O problema do fracasso escolar (ABREU, 2006; COLLARES; MOYSÉS, 1994; PATTO, 1999) é individualizado, negando-se as relações escolares estabelecidas ao longo do processo de escolarização. Questões interpretadas como problemas capazes de produzir o fracasso escolar são tratadas como déficits ou problemas biológicos, ignorando as diferentes influências dos modos de ser e de aprender.

Se na desde a invenção da escola moderna muitos tipos de exclusão foram realizados - como a de meninas, de crianças oriundas das classes populares e de alunos com deficiência - o que vemos no processo contemporâneo de medicalização na educação é a exclusão de alunos que não se encaixam no ideal de aluno, ideal este que é produzido, fabricado, inventado por uma série de estratégias pedagógicas que objetivam aproximar da maneira mais eficaz possível cada aluno ao padrão construído. Percebe-se como a escola ainda carrega enraizada em si, uma maneira disciplinar de funcionamento, um modo massificante e organicista de ver a criança e o adolescente que, apartada de suas condições culturais e sociais, é analisada de forma superficial e ambígua. Ao valorizar em demasia a ordem, a escola deixa de promover práticas de vivências democráticas para aplicar as normas disciplinares que possuem a finalidade de modificar comportamentos. 
O aluno "anormal" é, portanto, uma construção social, pois essa categoria surge em um determinado contexto revelando os comportamentos que rompem com as regras definidas pela cultura. $\mathrm{O}$ processo de medicalização transforma determinados modos de ser e aprender em sintomas de patologias. Dito de outra forma, o aluno anormal só o é dentro de um sistema de regras, de comparação, e o processo de medicalização torna-se um dispositivo para enquadrar os indivíduos nessas regras que criam o limite entre normalidade e anormalidade. Há um olhar pedagógico que procura razões no biológico para definir as (im)possibilidades de aprendizagem. À medida que os saberes médicos se inserem e se mantêm na dinâmica social e, consequentemente, no espaço escolar, as práticas pedagógicas se apropriam de um tipo específico de racionalidade em sintonia com esses saberes. Desse modo, a vida cotidiana, assim como a vida escolar, torna-se medicalizada (CHRISTOFARI, 2014).

Esse discurso medicalizante produz crianças "incapazes" de aprender, e cria a necessidade de um tipo de intervenção que deixa o pedagógico de lado e dá lugar a uma intervenção apenas relacionada aos saberes médicos. Pensar a relação do processo de medicalização na escolarização é abrir brechas para questionar que tipo de escola se tem construído e para quais alunos. A escola tem se mostrado como um lugar privilegiado desse processo de medicalização da vida e esse processo que tem se expandido às diferentes esferas da vida humana não é recente, pois desde o discurso higienista do início do século XX, a discursividade médica foi produzindo saberes sobre a prática pedagógica e formulou um projeto de educação pautado em seus discursos.

A medicalização instaura um processo explicativo que não mais questiona a escola, o método ou as condições de aprendizagem e de escolarização. Buscam-se na criança, em áreas de seu cérebro, em suas condutas e na dinâmica familiar as causas das dificuldades de aprendizagem e, consequentemente, a justificativa para a suposta incapacidade de acompanhamento dos conteúdos escolares. Para Garrido e Moysés (2011, p.150), “o que está em jogo é um violento processo de medicalização de crianças cujo desempenho na escola não corresponde exatamente ao padrão esperado". A criança com dificuldades é rotulada, procuram-se as causas, apresenta-se o diagnóstico e em seguida se prescreve basicamente dois tipos de intervenção: a medicação ou o acompanhamento terapêutico. A "dificuldade", que diz respeito ao processo de escolarização de muitos alunos, tem sido comumente nomeada como dislexia ou transtorno de aprendizagem, quando não se consegue especificar a dificuldade da criança, e passa a ser constituída como distúrbio. Considerada essa limitação como 
distúrbio, pouco ou nada a escola acredita poder intervir por meio das práticas pedagógicas (CHRISTOFARI, 2014).

A palavra do professor é uma peça importante no jogo de saberes e poderes que produzem modos de ser aluno. É um movimento disparador para visibilizar os enunciados que dão sentido a uma determinada forma de existir no contexto escolar e se perpetuam, se enraízam, tornando-se verdades incontestáveis no interior desta cultura. $\mathrm{O}$ discurso medicalizante no interior da escola, reproduzido por parte de gestores e professores, constitui-se em um desdobramento inevitável do processo de patologização dos problemas educacionais que têm servido como justificativa para a manutenção da exclusão de grandes contingentes de crianças pobres que, embora permaneçam nas escolas por longos períodos de tempo, nunca chegam a se apropriar de fato dos conteúdos escolares (MEIRA, 2012).

\begin{abstract}
Nos últimos anos, com a perspectiva da inclusão escolar, muitas crianças e adolescentes que antes estavam à margem do processo educacional estão indo para a escola e questionando os processos pedagógicos criados para trabalhar com a homogeneização. Esses alunos colocam em evidência a impossibilidade da existência do aluno ideal, de um único modo de aprender e se expressar, portanto, colocam em xeque as práticas pedagógicas construídas para serem desenvolvidas com um tipo de aluno ideal (CHRISTOFARI, 2014, p.43).
\end{abstract}

A perspectiva da função da escola valorizada atualmente, como lugar de educação para todos, é muito recente. Nos últimos anos, se tem vivenciado a presença cada vez maior, de crianças que comumente estariam à margem do processo de escolarização. A diversidade se encontra na escola colocando em xeque as práticas pedagógicas pautadas pelo princípio da homogeneização. Os múltiplos modos de ser e aprender intensificam a necessidade de construir categorias para os indivíduos, inserindo-os em uma lógica que os define como aqueles que são capazes de aprender e aqueles que supostamente não aprendem.

Moysés (2007) discute a Medicalização como uma “institucionalização invisível”, no qual crianças e adolescentes são presos em uma doença, confinados nesta instituição; e através dela, subjetividades são produzidas. As práticas sociais de maneira mais ampla, e as práticas escolares de modo específico, engendram domínios de saber que fazem aparecer novos conceitos e produzem novos modos de ser sujeitos. Caponi enfatiza: 
As classificações humanas geram efeitos nos sujeitos: cada classificação, cada diagnóstico, cada tipificação de pessoas, implica uma mudança no modo como agimos, como expressamos nossas emoções e sentimentos, no modo, enfim, de nos construirmos como sujeitos (CAPONI, 2010, p.140).

Atualmente presenciamos não mais um funcionamento da escola com a finalidade de excluir, mas, pelo contrário, de fixar o indivíduo, de mantê-lo nesse espaço e, ao mesmo tempo, de criar um dispositivo de controle, disciplinamento. É do corpo que se trata, de conhecê-lo para potencializar suas forças, sua utilidade e docilidade. "O corpo só se torna força útil se é ao mesmo tempo corpo produtivo e corpo submisso" (FOUCAULT, 2009, p.29). Os indivíduos são ligados a um aparelho de produção de saber, um saber sobre seu corpo, seu intelecto, suas condições e fragilidades. O efeito dessa produção de saber pode ser a exclusão como vemos acontecer na escola (alunos que evadem por terem passado muito tempo na escola sem aprender, alunos com deficiência, alunos com "problemas" de conduta, por exemplo). Mas uma exclusão dos espaços e do acesso à escola já não se configura mais como um grande desafio, mas sim a exclusão da possibilidade de falar, de pensar, de aprender, de criar e inventar novos modos de ser (CHRISTOFARI, 2014).

O "não aprender" pode ser uma forma de resistência ao ensino que não cativa, não envolve, não interessa. Classificar o aluno como "incapaz" e "desinteressado" é um modo de expropriá-lo de sua condição humana de transformação e aprendizado constante. $\mathrm{O}$ que precisa ser problematizado no âmbito escolar é que para além da pretensa anormalidade (o anormal, o atrasado, o hiperativo, o deficiente), há discursos sobre o anormal, o atrasado, o hiperativo e o deficiente. As consequências atuais desse tipo de compreensão sobre uma condição social do sujeito anormal, quando se pensa o sujeito escolar, têm desdobramentos importantes que não apenas definem a história escolar de cada um, mas também contribui com a configuração de uma história de vida que passa a ser marcada pela incapacidade e não pela possibilidade.

\section{Objetivo e Justificativa}

A pesquisa buscou investigar os discursos de professores da educação infantil acerca da medicalização na escola, em um contexto regional - na cidade de Sorocaba e localidades próximas. 
Partiu-se da hipótese da forte reprodução destes discursos por parte dos professores, devido aos constantes relatos de alunos do curso de Pedagogia do campus Sorocaba da UFSCar de crianças diagnosticadas e submetidas a tratamento com psicotrópicos já na educação infantil, presenciada em seus estágios e atividades de trabalho fora da Universidade.

Considera-se aqui que a escola sempre foi um lugar de produção de discursos que tornam visíveis, por meio dos rótulos, das etiquetagens, os efeitos dos processos de subjetivação que classificam e nomeiam os alunos como: bons, lentos, agitados, adiantados, prodígios, gênios, atrasados, deficientes, revoltados, hiperativos, depressivos. Para Foucault (2003, p.258), "somos inextricavelmente ligados aos acontecimentos discursivos. Em certo sentido, não somos nada além do que aquilo que foi dito há séculos, meses, semanas...”. Os discursos compõem um dispositivo estratégico de relações de poder-saber e a escola funciona atravessada por essas composições discursivas.

A investigação dos discursos (re)produzidos por professores permite observar as ramificação do poder psiquiátrico dentro da instituição escola e as singularidades que ele assume nesse contexto. Permite também a análise de eventuais resistências a sua crescente expansão para os domínios da infância.

O estudo foi focado na educação infantil por dois motivos. O primeiro deles refere-se à necessidade de se chamar a atenção para a precocidade com que crianças tem sido diagnosticadas com distúrbios psiquiátricos. O outro diz respeito às possíveis inadequações dos tratamentos propostos, tendo em vista que o metilfenidato, o psicotrópico que tem tido um crescimento exponencial de vendas no Brasil, como foi exposto anteriormente, só tem sua administração permitida para crianças acima de 6 anos de idade, não havendo estudos que comprovem a eficácia e segurança dessa substância no tratamento do TDAH em longo prazo, sendo necessário, para isso, um monitoramento cuidadoso do paciente (LEITE; BALDINI, 2011). Por este motivo, enquanto a medicalização de crianças acima de 6 anos - período correspondente ao ensino fundamental - torna-se mais defensável dentro de uma perspectiva biomédica, os diagnósticos de crianças abaixo desta idade e os tratamentos medicamentosos deveriam ser mais cautelosos, mesmo dentro dessa mesma visão biomédica (pelo menos em relação à prescrição do metilfenidato).

\section{Método}


Foram feitas entrevistas semi-abertas com seis professoras que atuam ou aturam em educação infantil. Inicialmente estavam previstas doze entrevistas no total, a serem realizadas com entrevistados voluntários contatados por meio de duas escolas públicas e duas privadas. Porém a exigüidade do tempo disponível e a dificuldade de contar com o apoio das escolas para se conseguir voluntários para a pesquisa levou a um número menor de entrevistas.

Optou-se por contatar professores voluntários para a pesquisa por meio da utilização de redes sociais. Foram enviados convites a professores participantes de grupos e comunidades existentes em redes sociais, que congregavam professores da região de Sorocaba. Diversas negociações para a realização da entrevista não tiveram sucesso, por falta de disponibilidade de horário dos voluntários ou falta de local adequado para a realização da entrevista. A desconfiança por parte dos professores também foi uma barreira aparente, motivando pedidos para visualização das perguntas antes da realização das entrevistas.

As entrevistas realizadas foram feitas com duas professoras da rede particular de ensino e com quatro da rede pública. Foram gravadas em áudio e posteriormente transcritas. Em relação aos aspectos éticos, foi explicitado o anonimato e o sigilo, documentados por meio de termo de consentimento livre e esclarecido, e obedecidas as normas da Resolução 466/12 do Conselho Nacional de Saúde.

O roteiro da entrevista abordou os casos de crianças diagnosticadas como portadoras de distúrbios que as professoras conheciam, suas concepções apresentadas sobre o fenômeno da medicalização, os relatos sobre casos de medicalização vividos no cotidiano escolar, incluindo os encaminhamentos feitos e os tratamentos recebidos por estes alunos.

As entrevistas foram analisadas com o método categorial de análise, conforme proposto por Bardin (1977). Tal método consiste na divisão dos dados obtidos na entrevista de acordo com o tema, formando grupos de acordo com a aproximação das falas. Desta forma a interpretação dos dados é facilitada pela melhor visibilidade. As categorias formadas foram as seguintes: segregação e rotulação das crianças com diagnóstico, críticas ao diagnóstico excessivo, relatos sobre os efeitos colaterais do medicamento em sala de aula, falas de viés medicalizante.

As entrevistadas (aqui com nomes fictícios) tem as seguintes idades, tempo de experiência e locais de trabalho: 
Professora 1: Virgínia, 26 anos, trabalha como professora de inglês há 6 meses em escola particular de educação infantil no ensino regular e dá aulas em escolas de inglês em escolas de idiomas da região em que mora em Sorocaba.

Professora 2: Catarina, 24 anos, experiência de 2 anos dando aulas eventuais na educação infantil da rede municipal de Sorocaba.

Professora 3: Maria, 35 anos, 10 anos de profissão, já trabalhou com crianças do maternal por 6 anos e trabalha há 4 anos na rede pública municipal de Sorocaba. Nesta, sempre trabalhou com II etapa da educação infantil, mas atualmente dá aulas no primeiro ano do Ensino fundamental.

Professora 4: Ana, 27 anos, trabalha há 5 anos na rede municipal da cidade de Votorantim com Educação infantil e leciona na parte da tarde no ensino fundamental em Sorocaba.

Professora 5: Ruth, 55 anos, 15 anos de profissão, trabalha numa escola particular de uma grande rede no Ensino Fundamental e já trabalhou com educação infantil.

Professora 6: Sandra, 41 anos, trabalha em escolas da rede pública de Votorantim e Sorocaba, professora há 16 anos, trabalha com Educação Infantil e ensino fundamental.

Cabe ressaltar que embora todas tenham tido experiência com educação infantil, nas entrevistas essas professoras frequentemente se referiram a crianças de outros níveis de ensino. Uma vez que o foco maior da pesquisa era a medicalização na escola com um todo - e não somente na educação infantil, que foi escolhida em virtude da investigação da precocidade dos diagnósticos - essas referências não foram consideradas como estando fora dos objetivos da pesquisa e, por este motivo, foram analisadas conjuntamente.

\section{Resultados}

Os discursos das professoras entrevistadas foram predominantemente de apoio 
explícito ou implícito à medicalização na escola, embora em alguns momentos tenham surgido críticas a esse processo. Supostos transtornos e distúrbios estão presentes em seus discursos acerca dos principais motivos pelo fracasso escolar das crianças, às vezes diretamente, por meio de sua nomeação, às vezes indiretamente, pela descrição dos sintomas comuns aos distúrbios mais conhecidos, em especial do TDAH.

Virginia, quando questionada sobre as maiores causas do insucesso das crianças na escola e sobre a dificuldade de alguns alunos para acompanhar os demais menciona um provável distúrbio a ser tratado, presente em uma criança que não consegue acompanhar bem o ritmo da aula, considerando a distração, um dos principais sintomas descritos do TDAH, como uma das causas do problema:

Entrevistadora: "Essas crianças não conseguem acompanhar por que tem um ritmo mais lento?"

Virgínia: "É, porque as atividades não são muito complexas né? Aí vezes é por ser mais lento, mais distraído. Eles tão numa idade, que como eles estão começando a entrar na escola, muitas vezes até tem algum distúrbio, alguma coisa e a mãe ainda tá vendo agora né?"

Ana considera diretamente os ditos "casos patológicos" como sendo causa de insucesso de seus alunos, porém em seu discurso reproduz a culpabilização mais forte da família, que não teria auxiliado e dado apoio pedagógico e emocional para essas crianças portadoras de "síndromes, déficits e deficiências". A instituição escolar permanece ilesa a críticas:

Ana: "Olha, eu acho assim, que todos são capazes igualmente. Pra mim o que faz a diferença no insucesso é a família, na verdade, falta de estímulo da família, principalmente... Claro que tem aqueles casos... patológicos né? De síndromes, deficiências, déficits.... mas assim, mesmo essas crianças, quando a família ajuda, apoia, dá todo apoio pedagógico e emocional também, a criança deslancha tanto quanto outra criança."

Já Sandra apresenta um discurso de apoio à medicalização, sem nenhuma crítica ou menção a efeitos negativos do tratamento. Relatando o caso de um aluno que não atendia as expectativas dela no desempenho escolar, refere que, tratada com medicação, a criança "melhorou", mostrando que tinha "potencial", revelando uma concepção que divide as crianças entre as que o teriam e as que não.

Sandra: "Melhora, melhora sim. Sem a medicação, eles tem dificuldade assim, até em se concentrar no que tão fazendo, em perceber o que os colegas estão fazendo naquele momento. Depois 
que eles começam o tratamento com o remédio, eles conseguem se concentrar mais, e o resultado acaba acontecendo mais depressa. Quando eu tive meu Juliano, quando eu chegava na escola e via ele na fila, quando eu olhava pra ele, pelo olhar dele eu já sabia que ele não tinha tomado remédio. Porque ele não conseguia se concentrar nem no boa tarde que eu dava pra ele. E depois, quando ele começou a tomar a medicação, quando foi assim, em maio ele já tava lendo, já tava escrevendo... Então, quer dizer, ele tinha o potencial, né? Mas ele dizia pra mim... ah, como é que era? Ele falava assim pra mim que era uma onda atrás da outra e que quando ele começava a tomar remédio, então a onda ficava mais devagar, ele definia isso pra mim."

Outro indicativo da visão medicalizante das professoras entrevistadas são os discursos que referendam ser função da escola o papel de acompanhamento próximo das crianças que demonstram alguma anormalidade no comportamento e seu encaminhamento para atendimento especializado. Isso parece ser entendido como um auxílio para o pleno desenvolvimento das mesmas, sem questionamento da origem da “anormalidade", considerando-se de antemão sua condição como fruto de um problema neurológico ou outro de saúde.

Virgínia: "Bem, principalmente na educação infantil que eles estão começando a ter uma vida social mais longe dos pais assim, acho que o papel da escola é mais tentar identificar né? E orientar o pai: '- Ah, eu percebo que ele é um pouco diferente nessas situações", né? Orientar pra que eles possam levar pro médico pra ter um diagnóstico certo mesmo né?".

Catarina: "O papel da escola não deveria ser só diagnosticar o problema, mas deveria ser esse cuidado como orientar os pais pra procurar um especialista, mas também oferecer recursos profissionais, especializados mesmo, pra atender essa criança, sem discriminação, sem separar, segregar, mas ela precisa dessa atenção especializada.”

A crença no correto diagnóstico dos supostos distúrbios por parte dos professores é tão forte que uma das entrevistadas chegou a mencionar que teria um "olhar mais sensível" que o do profissional de saúde, conseguindo diagnosticar a criança de forma mais apropriada que ele:

Entrevistadora: "Qual você acha que é o papel da escola nesse processo?"

Ana: "Então, o pediatra do posto que é aquele que já faz o atendimento pra aquele aluno que já está acostumado, é ele, depois do meu relatório, né? Aí ele vai avaliar e ver qual é o aluno e qual profissional, que pode ser que eu acredite, na sala de aula, pelas características do aluno, que pra mim ele precise de apoio neurológico, mas o pediatra ache que psicólogo já sanaria o problema. Mesmo com todas as características neurológicas do aluno, ele 
encaminha pra outro. Mas eu posso te falar uma coisa: O olhar do professor é muito mais sensível do que o médico, viu? Muitas vezes ele erra."

Em contraposição, Maria tem um discurso mais crítico quando questionada sobre o papel da escola no processo de descoberta de transtornos e denuncia o exagero no diagnóstico. Seus alvos de crítica são os próprios professores que estigmatizam a criança com comportamento desviante. Essa crítica, contudo, não significa que não existam para ela crianças que não devam ser encaminhadas para avaliação e tratamento para estes suspostos distúrbios:

Maria: "Então, o professor tem que geralmente levantar essa hipótese, né? Tudo bem que ultimamente tem tido um exagero né, qualquer comportamento que seja fora do que a gente deseja o professor já vai diagnosticando de hiperatividade, mas... realmente tem que levantar essa hipotese, né, porque tem crianças que você pode ajudar, e quanto mais cedo melhor, e também, no caso do municipal tem encaminhamento, né? Fazer o encaminhamento que esteja mais de acordo com o problema né, que a criança tem."

Ana e Ruth explicitam seus critérios para formular hipótese sobre supostos transtornos de seus alunos: àquele que se diferencia dos demais por ser muito distraído ou agitado é atribuído um possível transtorno para justificar tal disparidade e esse aluno é logo encaminhado para avaliação médica. Ana considera inclusive que "faz diagnósticos", o que deveria ser papel "dos médicos ou dos pais".

Ana: "Então, se na sua sala tem lá 30 alunos, mais ou menos, claro tem sempre aqueles mais calmos e os mais agitados, mas se daqueles 30 um se destaca ou porque não consegue acompanhar, ou porque só vive no mundo da lua e não consegue prestar atenção, ou porque tem alguma dificuldade de concentração, ou se não consegue ficar sentado, que durante sua roda de leitura tá sentado pra trás e não tá nem percebendo, porque na educação infantil eles amam a roda de leitura, então, se você começa a perceber que aquele aluno ou aquela aluna tá tendo essa discrepância dos outros, aí na hora você fala: 'Ah preciso encaminhar porque tá fora da normalidade', né, até das crianças mais agitadas mesmo tá fora normalidade. E o papel da escola é sim observar também educar, né? Mediar o conhecimento é também fazer esses diagnósticos que devia ser papel dos médicos ou dos pais, mas que infelizmente a escola tá virando assistencialista."

Ruth: "Então, quem normalmente descobre é a escola. Porque como você trabalha com grupos, você tem mais ou menos um parâmetro do que seria aceitável dentro de um grupo, aí se algum destoa do grupo, o professor já fica atento e foca naquela criança. Então a gente encaminha, né? 
A frequente estigmatização das crianças diagnosticadas com distúrbios psiquiátricos é apontado por algumas das entrevistadas. Virgínia cita um aluno seu que sofreu estigmatização pelo diagnóstico e pelo tratamento e que o próprio se defendia com o argumento de que "ter essa doença é normal, que tem um monte de gente que tem".

Virgínia: "Toda sala que você entra, pelo menos conta lá que 20,30\% tem um pouco mais de atraso ou .. é que agora eu não to, mas eu trabalhei num outro colégio particular também, que daí tinha, eu tinha desde o fundamental I até ensino médio também, e lá por ser de mais recursos financeiros, nossa, toda sala você via um monte de diagnóstico de hiperatividade, e eles sabem que eles tem. Tinha um que ele tomava remédio né, e era o único na sala que tinha hiperatividade, então os alunos ficavam tirando sarro dele, falavam 'Ah, hoje ele não tomou remédio' - tinha dia que ele vinha dormindo, e tinha dia que ele vinha muito agitado. Aí ele falava pra mim - 'Ah, professora, ele fica falando pra mim que eu não tomei remédio, tão tirando sarro, fala pra ele que essa doença é normal, que tem um monte de gente que tem'. Então eles sabem, e não tem mais vergonha né? É aberto... então tem de hiperatividade tem de déficit de atenção, a dislexia, tinha muito aluno com dislexia... e tem uma diferença né, a dislexia é mais pro português, aí tem uma outra que eu esqueci o nome que é de matemática. Mas tem um monte, nossa, não tem uma sala que não tenha.

Foram frequientes os discursos que falam do exagero de diagnósticos, que trazem à tona questões importantes para a análise do fenômeno da medicalização. As entrevistadas observam que há diagnósticos e tratamentos desnecessários, motivados, por exemplo, pelo simples fato do aluno não atender as expectativas dos professores ou por um comportamento considerado "inadequado" Mencionam, nesse sentido, que o diagnóstico de TDAH e o consequente tratamento medicamentoso "está na moda", e que por qualquer motivo fortuito já se considera que a criança seja portadora de tal transtorno.

Ruth: "Já, tem tido bastante e tem tido muito erro no diagnóstico, tá? Virou meio que moda: Ah, a criança tem déficit de atenção e hiperatividade, então, qualquer criança agitada ou fora do padrão os profissionais tão dando diagnóstico e a gente percebe, por a gente trabalhar há muito tempo, você percebe que eles estão exagerando um pouco no diagnóstico. Porque as vezes a criança é só um pouco mais agitada que as outras e eles estão fazendo diagnóstico, mais do que precisa. Porque daí com o transtorno o tratamento é com medicamento né? Aí as vezes a criança vai fazer o tratamento com medicamento e nem é o caso."

Entrevistadora: "E é muito comum casos de déficit de atenção?" 
Catarina: - "É aí que está, eu não sei se existe ou se é uma generalização, porque você põe uma criança hiperativa numa sala de aula e o professor reclama e a mãe leva num especialista e ele fala: "Ah, é déficit de atenção.",

Entrevistadora: "Mas existe muito caso de diagnóstico na escola que você trabalhou?"

Catarina: "Sim, tem bastante. Eu não sei se há uma generalização desse diagnóstico, porque nem sempre toda criança agitada ela tem déficit de atenção.. E é muito, muito recorrente assim, sabe? Aliás tem uma sala de aula que de vinte e cinco alunos, dez tem déficit de atenção. Diagnosticadas, né?"

Entrevistadora: "E você, na educação infantil, você já observou crianças com diagnosticos? De alguma coisa como, hiperatividade?"

Maria: “ Sim. Teve um ano, que foi até o ano que eu tava grávida. Que tinham três crianças que eu sabia que eram diagnosticadas, né? Que tomavam remédio, e três que tavam na base do floral. (risos). Porque os pais achavam que era hiperativo que tavam dando floral. E, mas não era hiperatividade, a maioria era comportamento mesmo, os pais não sabem, né, lidar com as crianças. Mas são crianças que assim, terríveis, que são anos que eu posso dizer assim, que foram terríveis, que eu não consegui trabalhar com a sala, sem auxiliar, né, aí foi complicado pra mim."

O exagero de diagnósticos levanta reflexões acerca do processo de

medicalização subjacente. Maria duvida do diagnóstico que deram para seus alunos, pondo em dúvida se o caso deles não seria de "desvio de comportamento", estabelecendo uma diferenciação entre o que seriam distúrbios psiquiátricos de meros problemas comportamentais, com os últimos sendo confundidos com os primeiros:

Entrevistadora: "Você acompanhou essas crianças sob tratamento, você achou que foi bom pra elas? O que você achou, você percebeu algum ponto positivo?"

Maria: Então, vou dizer pra você. Aqueles que estavam diagnosticados com hiperatividade, eu penso que na verdade era desvio de comportamento. E tinha um, ele era diagnosticado hiperativo, porém, acho que o medicamento deixava ele meio grogue, era como se sele não estivesse na aula. Até me assustei quando a mãe falou: - 'Ah ele é hiperativo'. Eu falei: -'Onde?' (risos) Mas é que ele já tava acabando já, tava naquele processo de tirar medicamento, sabe? De reduzir a dose? Então ele realmente não participava da aula, ele ficava muito sonolento."

Já Ruth, apesar de perceber os exageros no diagnóstico e considerar que muitos estão sob tratamento sem necessidade, reafirma os benefícios do tratamento, colocando em evidência aqueles que deixam a criança mais quieta e considerando ser esse um grande alívio para a criança, pois ela enxerga sua agitação como sendo uma expressão do desespero e angústia: 
Ruth: Eu sou bem a favor desse tratamento com medicamento, por que: porque quando a criança está nesse processo de agitação é algo que incomoda ela, ela fica num estado angustiante, dá pra ver que ela própria não se aguenta e aí ela tem que jogar pra fora, aí que ela corre, joga alguma coisa, porque ela fica num estado que ela não se suporta, então, com a medicação ela volta no seu eixo, ela consegue se concentrar, ela consegue ficar um tempo parada então a medicação faz bem no sentido de organização da criança né. Então existe, óbvio, efeitos colaterais que possam vir, mas o que traz de benefício pra criança, acho que compensa. Porque a gente vê em sala de aula depois aquela criança conseguindo se relacionar com os outros, tendo uma vida normal de criança, né? Ter uma vida como a de todo mundo, estar alí junto com todo mundo, porque é horrível pra quem tá de fora ver aquela criança se mexendo o tempo todo, e mexe o pé, e mexe o lápis, e derruba alguma coisa, e levanta e senta, sabe? Então, imagina o que essa criança tá sentindo por dentro, e com a medicação, parece brincadeira, mas tomou a medicação a criança vem centrada. E é uma medicação que toma, e fica por aquele tempo determinado, né? São seis horas o tempo de ação do remédio. Então por aquele tempo aquela criança consegue interagir, se concentrar, dar conta do que ela tem que fazer, então acho que vale a pena. Eu sou a favor da medicação. Embora a gente saiba que de repente vai ser pra vida toda, né? Mas é um benefício que vale a pena, vai trazer qualidade de vida, né, pra criança.

Outro ponto onde se percebe uma ambivalência dos professores em relação à medicalização da infância é o que se refere às possíveis consequências do uso da medicação, em especial do metilfenidato. As professoras reconhecem o fenômeno do superdiagnóstico, inclusive na educação infantil, e apontam com frequência reações adversas do uso de medicamentos, chegando a mencionar efeitos tal qual o conhecido na farmacologia com o nome de "zombie like" que consiste numa reação fisiológica que faz o paciente ficar contido em sí mesmo, que o deixa mais passivo, ou com sonolência em sala de aula, etc. Algumas mencionaram outras conseqüências negativas do tratamento, como a da dependência emocional ao remédio que a criança possa desenvolver.

Entrevistadora: - E você vê algum ponto negativo no tratamento do transtorno de déficit de atenção que é medicamentoso? Você vê alguma diferença na...

Virgínia: Muita. Muita, porque eles ficam, ficam meio bitolados assim, tem dia que eles vem muito sonolento, não faz nada, e tem dia que eles ficam muito agitados, não sei se é quando o remédio tá acabando, ou quando vai trocar, não sei. Às vezes tá muito agitado, e as vezes muito sonolento, não tem assim, meio termo. Não fica assim como os outros né? Fica muito agitado ou muito sonolento. 
Catarina: Tinha dias, que não sei se era o caso da mãe não dar o medicamento, não sei como a mãe dava esse medicamento (risos), porque sobre isso a gente não tem controle, né? Mas ela chegava meio atordoada, inclusive, tinha dia que ela chegava atordoada. Acho que no dia que ela tomava medicamento ela ficava meio sonolenta, e a mãe não dava medicamento com rigor, né?

Entrevistadora: É... e pontos positivos desses tratamentos que eles fazem?

Virginia: - Sinceramente, eu acho que o único ponto positivo..., eu não sei exatamente como o medicamento funciona no corpo e tudo, mas assim, é que quando ele não toma parece que ele fica sempre muito agitado, então ele tem um período de calma quando toma, né? Basicamente isso, ele consegue ter um período de calma.

Entrevistadora: E você percebe que ele, assim, ele fica calmo, ele fica mais concentrado?

Virgínia: Não fíca mais concentrado, só fica mais calmo, pelo contrário. Eu tive um que ele era hiperativo e ele era até esperto, ele responde aí ele simplesmente ele já não faz mais nada, assim.

A família, no discurso de todas as educadoras, é vista como um lugar de resistência à medicalização. Elas mencionam o receio dos pais frente ao diagnóstico e os vêem como super-protetores ou, mais recorrentemente, como relapsos ou preconceituosos. Para as entrevistadas, o papel da família é seguir as orientações da escola para encaminhar seus filhos para ajuda médica e, se possível, encorajar o tratamento. Algumas professoras percebem efeitos colaterais do metilfenidato nos alunos, mas os atribuem ao erro da prescrição ou de sua administração correta por parte da família, desta forma a acusando novamente de ser relapsa com o tratamento. A desconsideração das impressões e opiniões da própria família sobre a situação dos filhos também apareceu nas entrevistas. Esta aparece como um elemento a ser apenas convencido do problema da criança, desconsiderando o próprio testemunho dos pais quanto a alguma situação de stress ou conflito familiar que pode estar causando o comportamento dos filhos:

Ruth: "Quando a gente percebe que aquela criança está além do esperado, a gente já encaminha e aí depende da família. Tem família que eles aceitam, que procuram, quando a gente tem uma família que é parceira e que a gente pode trabalhar junto com ela e com o profissional, aí tudo flui tranquilo, né? [...] Agora, geralmente os pais não aceitam, aí quando os pais não aceitam, aí é mais complicado, porque a gente tem que fazer um trabalho primeiro com os pais, aí depois trazer o profissional, aí ele vai falar: 'não, mas meu filho não é isso que você está me apresentando', aí eles começam: 'não, é que a gente tá passando por isso, isso e aquilo', então ele sofreu tal coisa em casa, né? Então tentam arrumar mil desculpas, pra justificar aquela ação do filho, né? Mas aí a gente fala: não, mas isso é algo recorrente, 
não é de agora, isso tá acontecendo sempre. Então aí é um trabalho mais prolongado, né? A longo prazo. E aí dificulta [...] A gente tem de fazer esse outro trabalho de acolhimento com a criança né? Eles também tem medo da medicação, né? Eles falam: 'Ah, mas meu filho vai tomar remédio', né? E agora, não dá, etc. Então é complicado né? Tem que fazer todo esse trabalho com a família até ela entender que é preciso, que é o mais adequado pra gente poder fazer esse resgate com a criança depois. A gente tem que ser de tudo um pouco."

Ana: "Como eu disse pra você, já tem dois pontos quando a família não consegue enxergar a doença, né? Ou a família superprotege, e aí é tanto amor que ela não consegue enxergar que tem algo de errado com aquela criança ou é descaso, a criança é tão largada que a família não consegue perceber [...] Muitas vezes a família tapa o sol com a peneira justificando, usando o caso de alguém da família, as mães não entendem que cada caso é um caso, irmãos, mesmo, irmãos são diferentes. Aí eu não sei qual tratamento que vão passar pra ele. Mas eu tenho alunos de amigas, muitos casos de psicológo por déficit de atenção. A escola que encaminha né, porque ela é mais sensível... Então as vezes por amor, ou por descaso mesmo, a família acaba não enxergando."

Virgínia: "Olha eu acho que a família deveria ser a base fundamental pra ser diagnosticado o problema, e buscado todos os recursos necessários pra criança, pra maior desenvolvimento, intelectual e afetivo possível. O que eu percebo é que existe muito preconceito, que nem esse exemplo que eu citei, a mãe não busca atendimento especializado, mesmo a gente conversando com ela não aceita $o$ problema, que existe bastante preconceito e que existe também é que os pais são bastante relapsos com relação ao tratamento, que deve ser dado ao filho. Porque existe inclusive técnicas que você ensina na escola, pra que as crianças tenham um melhor aprendizado, mas que deve ser executadas em casa também e você percebe que em casa a criança não recebe essa atenção.e você percebe que em casa a criança não recebe essa atenção."

No discurso sobre a relação entre uma mãe e seu filho, Catarina observa que a partir do momento que a mãe "percebeu" que o filho era doente e começou a participar do processo, "tudo foi melhorando". Aqui, aparentemente o fator decisivo nem foi o tratamento em si, mas a atenção da mãe, que segundo a professora, passou inclusive a ser menos agressiva com a criança.

Catarina: "É a relação de parceria mesmo, porque tem muita família que observa alguma coisa de diferente, mas enquanto a criança não entra na escola, enquanto a professora não chama pra questionar como a criança é em casa ela não toma uma iniciativa, porque parece que ela não quer aceitar. $\mathrm{Pq}$ a partir do momento que a mãe aceita, o resultado acontece mais depressa, até a questão do diagnóstico ser fechado. Porque eu lembro que aquele aluno que eu te falei, a psicológa passou uns questionarios que eu tinha que responder sobre a sala de aula e sobre a família. A mãe tinha que fazer um e eu tinha que fazer outro pra ela ir confrontando, a partir do momento que a mãe começou a ir 
mesmo, começou a participar, tudo foi melhorando, até $\mathrm{o}$ relacionamento dele com a família, porque a família passou a entender. Porque ele era uma criança que se machucava muito porque ele não parava, tudo era curiosidade, tudo era brinquedo na mão dele: ele se machucava com lápis, ele punha a borracha na boca, a partir do momento que a mãe dele começou a perceber que tinha alguma coisa que precisava ser tratada, até o relacionamento dela com ele melhorou. Ela não foi mais tão agressiva com ele como ela era. Ela passou a entender né, que ele precisava de alguma ajuda."

Há casos descritos de crianças diagnosticadas e tratadas em que o receio frente ao estigma resultante faz com que as famílias por vezes escondam o diagnóstico e o tratamento do filho da comunidade escolar:

Sandra: "Porque as vezes a família já está mesmo buscando alguma coisa e não avisou a escola pra que o aluno já não entrasse na escola rotulado de alguma coisa. Porque a questão do rótulo é muito complicada também, a gente sabe."

\section{Conclusão}

Observou-se na pesquisa a tendência de reprodução nos discursos dos professores do processo da medicalização na escola. Embora em alguns momentos ocorram algumas críticas os excessos de diagnósticos e tratamentos, prevalece a visão de que o fundamento do processo é plenamente justificável. Nesse sentido, cabe à escola a descoberta e encaminhamento para tratamento médico de crianças com supostos distúrbios, cabendo inclusive o zelo para que os diagnósticos prévios sejam referendados, o que motiva a crítica aos profissionais da saúde que não reconhecem tais diagnósticos, como exposto em uma da falas: "O olhar do professor é muito mais sensível do que o médico, viu? Muitas vezes ele erra."

A medicalização na escola é vista predominantemente pelas entrevistadas como algo que propiciaria o pleno desenvolvimento dos alunos, considerando-se de antemão sua condição como fruto de um problema neurológico ou outro de saúde, o que isenta a escola de responsabilidade frente às dificuldade de escolarização apresentadas. $\mathrm{O}$ "período de calma" que se segue à administração do metilfenidato por exemplo, é visto como algo positivo, ainda que efeitos colaterais sejam constantemente observados, casos que são atribuídos à erros de prescrição ou de dosagem, mantendo-se, portanto, a o discurso de que o fundamento da medicalização é correto.

Nos discursos das professoras, a família é apontada como a instância que resiste à medicalização, sendo essa resistência claramente negativada por elas: caso não 
aceitem as sugestões de encaminhamento referentes aos supostos distúrbios, os pais passam a ser vistos como super-protetores, preconceituosos ou relapsos,. Deslegitimase, dessa forma, possíveis críticas aos próprios fundamentos da medicalização feitas pelos pais e reafirma-se o papel disciplinar da escola, aqui referendado pelo discurso bimédico.

Observa-se na pesquisa, portanto, como a presença da nosografia médica no cotidiano das instituições escolares é inspiradora de práticas que criam e sustentam as condições de entendimento de um aluno que não corresponde ao modelo de aluno ideal como um aluno com um potencial distúrbio. No âmbito escolar, instaura-se um processo explicativo que não mais questiona a escola, o método ou as condições de aprendizagem e de escolarização. Busca-se na criança, em áreas de seu cérebro, em suas condutas e na dinâmica familiar as causas das dificuldades de aprendizagem e, consequentemente, a justificativa para a suposta incapacidade de acompanhamento dos conteúdos escolares. Isso permite que a escola mantenha práticas educativas que emolduram condutas e modos de aprender dentro dos padrões escolares de normalidade.

Considera-se aqui que refletir sobre as relações pedagógicas atinentes à inclusão e sensíveis à diversidade humana é problematizar a organização da sociedade contemporânea, os modos de olhar para o outro criando categorias de sujeitos e discursos sobre eles: o louco, o deficiente, o marginal, o delinquente, o anormal. Afastar-se da predisposição de criar rótulos e categorias de sujeitos é uma tarefa que exige uma mudança cultural, potencializando os movimentos de ruptura em relação a essas noções que vão se naturalizando, tornando-se familiares. Daí a importância de pesquisas que analisem de forma crítica o processo de medicalização que afeta a instituição escola.

\section{MEDICALIZATION AT SCHOOL FROM EARLY CHILDHOOD EDUCATION TEACHER'S PERSPECTIVE: A STUDY IN SOROCABA, BRAZIL}


ABSTRACT: The paper is based on theoretical considerations about the process of medicalization in general and inside schools in particular, and presents a qualitative research done in the region of Sorocaba-SP. The research involved the analysis of six semi-structured interviews done with teachers of early childhood education, with the aim of investigating their speeches about the process of medicalization in school. The results showed that these teachers preceived the intensification of this process in the schools where they work. The medicalization was implicitly or explicitly supported by them and was seen predominantly under a positivised bias. Potential problems, such as overdiagnosis or possible side effects of medications, were seen as the result of wrong diagnoses and prescriptions, and not as a result of the medicalization process itself. Families that resist this process were negatively presented, as overprotective or neglectful regarding the proper care of their children. Criticism under the inability of schools to deal with children who flee to the ideal student model did not appear, which shows the process of medicalization linked to a process of disciplinarization in school, by assigning abnormality of the dissenting students regarding what is expected.

KEYWORDS: Medicalization. Disciplinarization. Normality. Early childhood education.

\section{REFERÊNCIAS}

ABREU, M. H. R. M. Medicalização da vida escolar. 2006. 114 f. Dissertação (Mestrado em Educação) - Universidade Federal do Estado do Rio de Janeiro, Rio de Janeiro, 2006.

AGUIAR, A. A. A psiquiatria no divã: entre as ciências da vida e a medicalização da existência. Rio de Janeiro: Relume Dumará, 2004.

BARDIN, L. Análise de conteúdo. Lisboa: Edições 70, 1977.

BARROS, J. A. C. Ampliando espaços para a "medicalização": instrumento para desfrute de melhores níveis de vida? In: CAPONI, S. et al. Medicalização da vida: ética, saúde pública e indústria farmacêutica. Palhoça: Unisul, 2010. p.89-95.

BASTOS, H. P. O psicólogo da saúde pública numa proposta de trabalho interinstitucional: a queixa escolar como elo de ligação. 1999. 158 f. Dissertação (Mestrado em Psicologia Social) - Universidade de São Paulo, São Paulo, 1999.

BIRMAN, J. Mal-estar na atualidade: a psicanálise e as novas formas de subjetivação. 3.ed. Rio de Janeiro: Civilização Brasileira, 2001.

CAPONI, S. et al. Medicalização da vida: ética, saúde pública e indústria farmacêutica. Palhoça: Unisul, 2010.

CHRISTOFARI, A. C. Modos de ser e de aprender na escola: medicalização (in)visível?. 2014. 173 f. Tese (Doutorado em Educação) - Programa de Pós-Graduação em Educação, Universidade Federal do Rio Grande do Sul, Porto Alegre, 2014. 
COLLARES, C. A. L. ; MOYSES, M. A. A. A Transformação do Espaço Pedagógico em Espaço Clínico: a patologização da educação. Idéias, Campinas, v.23, p.25-31, 1994.

FOUCAULT, M. Microfísica do Poder. 29. reimpr. Rio de Janeiro: Edições Graal, 2011.

Vigiar e Punir: nascimento da prisão. 37.ed. Petrópolis, RJ: Vozes, 2009.

Diálogo sobre o poder. In: FOUCAULT, M. Estratégia, poder-saber. Rio de Janeiro: Forense Universitária, 2003. p.253-266. (Coleção Ditos e Escritos, IV).

GARRIDO, J.; MOYSÉS, M. A. A. Um Panorama Nacional dos estudos sobre a medicalização da aprendizagem de crianças em idade escolar. In: CONSELHO REGIONAL DE PSICOLOGIA DE SÃO PAULO. Grupo Interinstitucional Queixa Escolar. Medicalização de crianças e adolescentes: conflitos silenciados pela redução de questões sociais a doenças de indivíduos. São Paulo: Casa do Psicólogo, 2011. p.149-162.

GUARIDO, R. A medicalização do sofrimento psíquico: considerações sobre o discurso psiquiátrico e seu efeitos na Educação. Educação e Pesquisa, São Paulo, v.33, n.1, p.115-161, 2007.

ILLICH, I. A expropriação da saúde: nêmesis da Medicina. 3.ed. Rio de Janeiro: Nova Fronteira, 1975.

LEITE, E. G.; BALDINI N. L. F. Transtorno de Déficit de Atenção/Hiperatividade e Metilfenidato: Uso necessário ou induzido? Gestão e Saúde, Brasília, v.2, n.1, p.1-14, 2011.

LINS, F. R. S. A psicologização da psicanálise na educação: um estudo de sua origem em S.P. In: O DECLÍNIO DOS SABERES E O MERCADO DO GOZO, 8., 2010, São Paulo. Anais online... São Paulo: FE/USP, 2010. Disponível em: <http://www.proceedings.scielo.br/scielo.php?script=sci_arttext\&pid=MSC0000000032 010000100019\&lng=en\&nrm=abn>. Acesso em: 17 fev. 2015.

LUENGO, F. C.; CONSTANTINO, E. P. A Vigilância Punitiva: a postura dos educadores no processo de patologização e medicalização da infância. Vertentes, Assis, v.8, p.122-126, 2010.

MACHADO, R. Danação da Norma: Medicina social e a constituição da Psiquiatria no Brasil. Rio de Janeiro: Edições Graal, 1978.

MEIRA, M. E. M. Para uma crítica da medicalização na educação. Revista Semestral da Associação Brasileira de Psicologia Escolar e Educacional, São Paulo, v.16, n.1, p.135-142, 2012.

MOYSÉS, M. A. A. A institucionalização invisível: crianças que não aprendem na escola. 2.ed. Campinas: Mercado de Letras, 2007. 
MOYSÉS, M. A. A.; COLLARES, C. A. L. A medicalização na educação infantil e no ensino fundamental e as políticas de formação docente. A medicalização do nãoaprender-na-escola e a invenção da infância anormal. Caxambu, 2008. Anais online... ANPED. Disponível em: <http://31reuniao.anped.org.br/4sessao_especial/se\%20$\% 2012 \% 20-\% 20$ maria\%20aparecida\%20affonso\%20moyses\%20\%20participante.pdf>. Acesso em: 17 nov. 2014.

ORTEGA, F. et al. A Ritalina no Brasil: produções, discursos e práticas. Interface: Comunicação, saúde, educação, Botucatu, SP, v.14, n.34, p.499-510, 2010.

PATTO, M. H. S. Para uma crítica da razão psicométrica. In: PATTO, M. H. S. Mutações do cativeiro: escritos de psicologia e política. São Paulo: Hacker: EDUSP, 2000. p.65-83.

. Formação profissional, compromisso político e luta antimanicomial. In: FERNANDES, M. I. A.; SCARCELLI, I. R.; COSTA, E. S. Fim do século: ainda manicômios? São Paulo: Ed. do IPUSP, 1999. p.109-122.

A produção do fracasso escolar: histórias de submissão e rebeldia. São Paulo: T.A. Queiroz, 1990.

ROUDINESCO, E. Por que a Psicanálise? Rio de Janeiro: Jorge Zahar, 2000.

UNITED NATIONS INTERNATIONAL NARCOTICS CONTROL BOARD [UNINCB]. Psychotropic substances: statistics for 2006 - Assessments of Annual Medical and Scientific Requirements for Substances in Schedules II, III and IV of the Convention on Psycho. New York: United Nations Publications, 2008. 368 p. 